\title{
PENGALAMAN DISFUNGSI SEKSUAL PADA KLIEN PRIA DENGAN ULKUS DIABETIKUM
}

\author{
Haifah Maulida*, Handono Fatkhur Rahman, \\ Setyo Adi Nugroho, Sri Astutik Andayani, Abdul Hamid Wahid \\ Program Studi S1 Keperawatan Fakultas Kesehatan Universitas Nurul Jadid Paiton \\ Probolinggo 67291, Jawa Timur Indonesia \\ E-mail: haifahmaulida97@gmail.com
}

\begin{abstract}
ABSTRAK
Latar Belakang: Diabetes melitus (DM) menjadi salah satu penyebab organis utama gangguan fungsi seksual pria yang berefek pada kompleksitas gangguan seksual. Tujuan: mengetahui secara mendalam tentang disfungsi seksual pada klien pria dengan ulkus diabetikum. Metode: Penelitian ini menggunakan metode kualitatif dengan pendekatan fenomenologis dan wawancara sebagai teknik pengumpulan data. Penelitian ini melibatkan 7 partisipan yang dipilih dengan purposive sampling. Kriteria inklusi pada penelitian ini adalah klien pria ulkus diabetik, usia 30-60 tahun, dan bersedia menjadi partisipan. Analisis data menggunakan pendekatan analisis selektif dan focusing (the selective or highlighting approach). Hasil: enam tema teridentifikasi dalam penelitian ini diantaranya pandangan tentang seksual pada kehidupan pria, perubahan seksual yang dialami, dampak perubahan seksual, perilaku mengatasi masalah akibat perubahan seksual, harapan terhadap kondisi perubahan seksual, dan respons support system. Kesimpulan: Klien pria dengan ulkus diabetikum mengalami disfungsi seksual yang berdampak pada diri dan pasangan. Klien berupaya mencari cara penyelesaian sesuai persepsinya dan mengharapkan dukungan keluarga untuk memperbaiki fungsi seksual mereka. Hasil penelitian ini dapat digunakan untuk perawat sebagai dasar penentuan tindakan preventif yang sesuai agar tidak terjadi komplikasi yang lebih cepat yang akan menimbulkan gangguan/disfungsi seksual. Selain itu dapat juga digunakan untuk penyusunan program pelayanan kesehatan seksual, dengan menyediakan ruang khusus untuk konsultasi seksual, layanan konsultasi paripurna, hotline service, dan home based care untuk menfasilitasi minimnya fasilitas pelayanan seksual.
\end{abstract}

Kata kunci: Diabetes Melitus, ulkus diabetikum, disfungsi seksual

\section{The Experience of Sexual Dysfunction in Male Clients with Diabetes Ulcers}

\section{ABSTRACT}

Background: Diabetes mellitus (DM) is one of the main organic causes of male sexual dysfunction. Objective: This research is to find out about sexual dysfunction in male clients with diabetes ulcers. Methods: This study used a qualitative method using phenomenology and interviews as data collection techniques. There were 7 participants selected with using purposive sampling. The inclusion criteria in this study were male clients with diabetes ulcers, aged between 30-60 years, and agree to participate. Data analysis using selective or focused (the selective or highlighting approach). Results: Six themes identified in this study include sexual perspective in men's life, experienced sexual changes, effect of the sexual changes, behaviors to overcome the effect of sexual changes, expectation related to the condition of sexual changes, and support system response. Conclusion: male clients with diabetic ulcers experience sexual dysfunction that affects themselves and their partners. Clients try to find solutions to their perceptions and expect family support to improve their sexual function. The results of this study could be used for nurses as a basis for determining appropriate precautions to prevent faster complications that will cause sexual disorders/dysfunction. In addition, it could also be used for the preparation of sexual health service programs, by providing special space for sexual consultation, plenary consultation services, hotline services, and home-based care to facilitate the lack of sexual service facilities.

Keywords: Diabetes mellitus, diabetic ulcer, sexual dysfunction 


\section{LATAR BELAKANG}

Penyakit Tidak Menular (PTM) sudah menjadi masalah kesehatan masyarakat, baik secara global maupun nasional. Salah satu PTM yang menyita banyak perhatian adalah Diabetes Melitus (DM). DM merupakan salah satu permasalahan kesehatan terbesar di dunia karena setiap tahunnya terjadi peningkatan kasus (Rahman \& Sukmarini, 2017). DM merupakan penyakit kronis yang masih menjadi masalah utama dalam dunia kesehatan khususnya di Indonesia (Permatasari, Sudargo, \& Purnomo, 2015). Prevalensi DM terus mengalami peningkatan di dunia, baik di negara maju maupun negara sedang berkembang. Jumlah penderita yang mengalami DM tipe II merupakan kelompok yang terbanyak, mencapai kurang lebih 90-95\% dari pengidap DM di dunia (Taluta \& Hamel, 2014). Menurut data International Diabetes Federation (IDF), ada 425 juta orang dengan DM di seluruh dunia dan itu diperkirakan akan mencapai 629 juta pada tahun 2045 (IDF, 2017). Pada tahun 2015, Indonesia menempati peringkat ketujuh dunia untuk prevalensi penyandang diabetes tertinggi bersama dengan China, India, Amerika Serikat, Brazil, Rusia, dan Meksiko dengan jumlah estimasi orang dengan diabetes sebesar 10 juta (Amelia, 2017). Berdasarkan hasil riset kesehatan dasar tahun 2018, prevalensi DM berdasarkan diagnosis dokter pada penduduk umur $>15$ tahun menurut provinsi, tahun 2013-2018 Jawa Timur termasuk urutan ke-5 (Kementerian Kesehatan Republik Indonesia, 2018).

DM akan mengakibatkan komplikasi, salah satunya gangguan pada aktivitas seksualitasnya (Mahendra, 2008). Penderita DM tipe 2 juga mempunyai kebutuhan seksual seperti orang pada umumnya. Namun, ada beberapa masalah seksual seperti resiko terkena impotensi (disfungsi ereksi) pada laki-laki setelah mereka mengalami diabetes selama bertahuntahun. Hal tersebut disebabkan oleh adanya neuropati (kerusakan fungsi saraf) atau rendahnya suplai darah ke penis (Fox, 2010). Disfungsi seksual yang terjadi pada pria merupakan salah satu gangguan yang dapat menyebabkan penurunan fungsi seksual.

Gangguan fungsi seksual ini bisa terjadi pada satu atau lebih siklus respons seksual. Respons seksual yang terjadi pada pria lebih bersifat linier, yaitu eksitasi (perangsangan), plateau (dataran tinggi), orgasme, dan resolusi (Muchtar, 2009). Perubahan seksual ada kaitannya dengan frekuensi kegiatan seksual dan perilaku, kesulitan beraktivitas dan fungsi seksual, sikap terhadap seks, dan detail tentang hubungan seksual saat ini. Pentingnya pemenuhan kebutuhan seksualitas sangat berpengaruh pada kehidupan (Hinchliff dkk, 2018). Berdasarkan hal di atas, maka diperlukan gambaran secara mendalam dan menyeluruh tentang pengalaman disfungsi seksual pada klien pria dengan ulkus diabetikum di RS Kabupaten Probolinggo.

\section{METODE}

Desain penelitian yang digunakan adalah kualitatif dengan pendekatan fenomenologi. Penelitian dilakukan pada bulan Februari 2019 di RS Kabupaten Probolinggo setelah melalui proses perijinan. Pada penelitian ini didapatkan 7 partisipan yang dipilih dengan purposive sampling. Kriteria inklusi pada penelitian ini adalah klien pria dengan ulkus diabetik, usia 30-60 tahun, dan bersedia menjadi partisipan dari awal hingga selesai.

Instrumen penelitian adalah peneliti sendiri, menggunakan pedoman wawancara, dan alat perekam. Wawancara dilakukan 1-2 kali di ruangan tertutup dengan tetap mempertimbangkan prinsip etika penelitian. Data dikelola dan dianalisis melalui tahapan 
penyusunan transkip, pembacaan transkrip berulang, penentuan dan pembuatan kategori, formulasi tema, deskripsi lengkap dan penyusunan laporan hasil analisis. Keabsahan data menggunakan triangulasi sumber untuk mengecek kebenaran data yang diperoleh dari informan, yaitu petugas kesehatan di ruang penyakit dalam dan keluarga dari pasien yang mengalami ulkus diabetikum. Wawancara berlangsung selama 15-30 menit di tempat yang sudah disepakati. Peneliti menjelaskan prosedur penelitian dan memberikan informed consent sebelum wawancara. Penelitian ini juga telah lulus uji etik dari Fakultas Kesehatan Universitas Nurul Jadid (NO: NJT06/028/F.Kes/S.Ket/ 12.2018).

\section{HASIL}

Partisipan dalam penelitian ini berjumlah 7 orang partisipan pria dengan ulkus diabetikum. Karakteristik partisipan tersebut disajikan dalam Tabel 1. Dari tersebut dapat dilihat bahwa rentang usia partisipan adalah 38-53 tahun, sebanyak tiga orang berlatar pendidikan S1, tiga orang SMA dan satu orang SMP. Seluruh partisipan berstatus sudah menikah.

Hasil penelitian menunjukkan bahwa ada 6 tema yang diperoleh, yaitu: (1) pandangan tentang seksual pada kehidupan pria, tema tersebut terdiri dari dua sub tema diantaranya: kebutuhan primer dan kebutuhan sekunder; (2) perubahan seksual yang dialami, terdiri dari lima sub tema diantaranya gangguan ereksi, gangguan ejakulasi, gangguan hasrat, perubahan kenikmatan, dan perubahan fisik; (3) dampak perubahan seksual, yang terdiri dari tiga sub tema yaitu dampak sosial, dampak hubungan dengan pasangan, dan respon psikologis; (4) Perilaku mengatasi masalah akibat perubahan seksual, ada tiga sub tema yaitu cara pengobatan, aktivitas spiritual dan aktivitas lain; (5) harapan terhadap kondisi perubahan seksual, terdiri dari dua sub tema yaitu harapan atas diri sendiri dan harapan kepada istri; (6) respon support system, terdiri dari dua sub tema diantaranya: respon istri, respon keluarga.

\section{Pandangan tentang seksual pada kehidupan pria \\ Pandangan tentang seksual pada} kehidupan pria adalah bagaimana partisipan memandang apa sebenarnya seksualitas, fungsi seksual dan seksual yang sehat. Dari penelitian ini didapatkan hasil bahwa partisipan memandang seksual merupakan hal penting bagi hidupnya, sebagai kebutuhan primer kedua setelah makan dan minum, serta merupakan suatu keharusan bagi pria. Berikut ini ungkapan partisipan:

“.... dalam kehidupan sangat penting klo ngk, saya ngak punya anak sampek sekrang" (B2)

"Menurut saya ya penting, apalagi bagi pria"(B7)

"Seksual khususnya pada laki-laki adalah kebutuhan utama"(B1)

"Hubungan anatara laki-laki dengan si perempuan itu kebutuhan utama"(B4)

"Seksual itu yang keharusan, gunanya untuk memperbanyak keturunan"(B3)

\section{Perubahan seksual yang dialami}

Perubahan seksual yang dialami partisipan (B1) yaitu mengalami ereksi yang kurang atau tidak maksimal. Mereka butuh rangsangan yang lebih lama terlebih dahulu untuk bisa sampai pada munculnya ereksi. Waktu untuk memulai ereksi pun lebih lama dari sebelum sakit, namun hal ini masih tetap tidak maksimal bahkan kadang-kadang kendor. Hal ini sebagaimana pernyataan partisipan sebagai berikut:

"Setelah positif kencing manis oleh dokter rasanya tidak terlalu tegang"(B1)

"....Ngak bisa lama, saat tegang kalau ngak langsung berhubungan ya cepet kendor"(B1) 
Ketidakmampuan ereksi secara maksimal ini menyebabkan partisipan tidak mampu mempertahankan ereksi lebih lama lagi, beberapa menit langsung kendor kembali dan tidak bisa ereksi kembali. Ketika salah satu partisipan ingin melakukan hubungan seksual dengan istri, jika tidak langsung dilakukan maka penis yang telah ereksi akan menurun kembali. Berbeda dengan beberapa partisipan lain yang masih bisa memulai ereksi walau tidak bertahan lama, dua partisipan (B6, B7) tidak bisa ereksi sehingga butuh upaya yang lebih dan bahkan terkadang muncul kegagalan dan kecewaan. Berikut ungkapannya:

".... Berdirinya ngak bisa mbk"(B6)

".... Ngak bisa berdiri seperti sebelum sakit"(B7)

Seiring dengan disfungsi seksual yang dirasakan, beberapa partisipan mengatakan mengalami ejakulasi dini baik itu cepat mengeluarkan sperma sebelum coitus atau jumlah sperma yang keluar sedikit sampai tidak terjadi ejakulasi meskipun sudah merasa puas dan tidak berhubungan seks dalam waktu yang lama.

"keluarnya terlalu cepat"(B1)

".... Cuma sebentar"(B2)

"spermanya keluarnya cepat sekitar 1,2,3 menit gitu"(B5)

\section{Dampak perubahan seksual}

Perubahan seksual yang dialami partisipan akan berdampak pada pola hubungan dengan pasangan, terjadi perubahan peran sebagai suami. Dampak sosial terlihat pada partisipan bahwa gangguan seksual yang dialaminya membuat partisipan malu karena tidak bisa memuaskan istrinya dengan sepenuhnya. Sesuai pendapat partisipan (B1) yang mengatakan malu terhadap perubahan seksualnya yang dialami untuk bercanda-canda sama istri sudah malas karena takut menyinggung si istri. Berikut ini ungkapan partisipan:

"Saya merasa malu...."(B1)

\section{Perilaku mengatasi masalah akibat perubahan seksual}

Berbagai upaya dilakukan, mulai dari mengkonsumsi obat baik untuk mengatasi diabetesnya maupun khususnya pada gangguan seksual. Selain itu, partisipan juga ada yang melakukan pengaturan diet dan mengkonsumsi telur. Berikut ini ungkapan partisipan:

"telur bebek untuk dikonsumsi sebagai jamu"(B1)

"diet saya diperketat biar cepet sembuh lukanya"(B3)

Partisipan (B4, B6) juga melakukan spiritual dengan dzikir untuk mengatasi akibat perubahan seksualnya pada dirinya dan partisipan bisa menahan nafsunya. Berikut ini ungkapan dari partisipan:

"saya bisa lebih deket lagi dengan tuhan, melakukan dzikir..."(B4)

"pastinya selalu dzikir"(B6)

\section{Harapan terhadap kondisi perubahan seksual}

Partisipan mengharapkan adanya perubahan dari diri sendiri dan istri sebagai pasangan. Harapan atas diri sendiri ditekankan pada kemampuan bersabar dan mendapatkan rizki yang banyak untuk memenuhi kebutuhan berobat sehingga tetap dapat mengontrol kadar gula darah dan penyakitnya, sehingga fungsi seksualnya juga dapat berubah lebih baik. Selain itu partisipan juga berharap sembuh dan kembali berfungsi. Berikut ini ungkapan dari partisipan:

“...Lebih sabar juga"(B5)

"semoga saya selalu sabar...."(B6)

"mempunyai rezki banyak dan bisa berobat"(B2) 


\section{Respon support system}

Pasangan hidup menjadi support system terdekat bagi partisipan. Respon apapun yang ditunjukkan akan membuat perubahan yang sangat penting bagi partisipan untuk melalui hari-harinya bersama permasalahan yang dialaminya. Dukungan pasangan yang diterima seseorang dapat berupa dukungan informasional, perhatian, fasilitas, dan dukungan emosional (Suardana, Rasdini, \& Kusmarjathi, 2015). Hasil penelitian sebelumnya menunjukkan bahwa dukungan pasangan merupakan faktor paling dominan dalam mempengaruhi kadar gula darah dan prediktor terkuat dalam mempengaruhi hasil kesehatan pasien, utamanya dengan penyakit kronis (Isworo \& Saryono, 2010).

Table 1. Karakteristik Partisipan

\begin{tabular}{llllll}
\hline Kode & Jenis Kelamin & Usia & Pendidikan & Pekerjaan & Status \\
\hline B1 & Laki-laki & 40 & S1 & PNS & Menikah \\
B2 & Laki-laki & 45 & S1 PAl & Guru agama & Menikah \\
B3 & Laki-laki & 46 & SMA & Bengkel & Menikah \\
B4 & Laki-laki & 53 & SMP & Pedagang & Menikah \\
B5 & Laki-laki & 48 & SMK & Wiraswasta & Menikah \\
B6 & Laki-laki & 38 & SMA & Wiraswasta & Menikah \\
B7 & Laki-laki & 47 & S1 & PNS & Menikah \\
\hline
\end{tabular}

\section{DISKUSI}

Tema pertama dalam penelitian ini (pandangan tentang seksual pada kehidupan pria) dapat diartikan bahwa partisipan menganggap seksual adalah berhubungan badan. Hal ini sesuai dengan pendapat Rowland \& Incrocci (2008) bahwa fokus dan orientasi seksual pada pria berbeda dengan wanita, pria menganggap fokus dari seksualitas adalah area genetalia dalam arti berhubungan badan (Rowland \& Incrocci, 2008). Pandangan tentang seksual yang sehat menjadi titik pemikiran bagi pria. Menurut Rahardjo, Saputra, \& Hapsari (2015), pria dikatakan sebagai figur yang tergolong rentan terhadap perilaku seks berisiko, bahkan lebih rentan dibandingkan wanita. Pria tergolong proaktif secara 
seksual, mengendalikan kontak seksual dan juga lebih permisif dalam hal seksualitas. Sementara itu, kepemilikan pasangan dalam jumlah banyak dipandang sebagai suatu pengakuan seksual terutama bagi pria. Memiliki pasangan seks dalam jumlah banyak membuat pria merasa hebat dan mendapatkan pengakuan dari teman sebaya (Rahardjo, Saputra, \& Hapsari, 2015). Teori lain mengatakan bahwa seks merupakan salah satu faktor penting dalam kehidupan manusia dan makhluk hidup lainnya terutama bagi pria. Seks akan membawa manusia kepada kebahagiaan dan kedamaian (Ahsin, 2007). Hasil penelitian ini juga sependapat dengan Bijlsma-Rutte, dkk (2017) bahwa libido seorang pria lebih tinggi dibandingkan dengan seorang perempuan $(66,8 \%$ dan 47,2\%) (Bijlsma-Rutte, dkk, 2017). Pada akhirnya terjadi perubahan gangguan pada seksualitasnya, maka pria akan merasa terganggu, harga diri dan semangat turun.

Maslow (1943) menjelaskan adanya kebutuhan manusia berupa kebutuhan mencintai dan dicintai (love and belongingness needs). Kebutuhan cinta adalah kebutuhan dasar yang menggambarkan emosi seseorang. Kebutuhan ini merupakan suatu dorongan dimana seseorang berkeinginan untuk menjalin hubungan yang bermakna secara efektif atau hubungan emosional dengan orang lain. Dorongan ini akan makin menekan seseorang sedemikian rupa, sehingga ia akan berupaya semaksimal mungkin untuk mendapatkan pemenuhan kebutuhan akan cinta kasih dan perasaan memiliki (Asmadi, 2008).

Dari hasil tema kedua dalam penelitian ini, yaitu perubahan seksual yang dialami, menunjukkan bahwa perubahan seksual yang dialami partisipan berupa ereksi yang kurang atau tidak maksimal, mereka butuh rangsangan yang lebih lama terlebih dahulu untuk bisa sampai pada munculnya ereksi, waktu untuk memulai ereksipun lebih lama dari sebelum sakit, namun hal ini masih tetap tidak maksimal bahkan kadang-kadang kendor.

Ketidakmampuan ereksi secara maksimal ini menyebabkan partisipan tidak mampu mempertahankan ereksi lebih lama lagi, beberapa menit langsung kendor kembali dan tidak bisa ereksi kembali. Ketika salah satu partisipan ingin melakukan hubungan seksual dengan istri, jika tidak langsung dilakukan maka penis yang telah ereksi akan menurun kembali. Berbeda dengan beberapa partisipan lain yang masih bisa memulai ereksi walau tidak bertahan lama, dua partisipan (B6, B7) tidak bisa ereksi sehingga butuh upaya yang lebih dan bahkan terkadang muncul kegagalan dan kecewaan.

Keluhan disfungsi ereksi ini menjadi masalah yang paling banyak muncul pada gambaran disfungsi yang dialami oleh partisipan. Banyak faktor resiko yang menyebabkan disfungsi ereksi ini, diantaranya beberapa partisipan mengalami hipertensi (B2, B4), dan dari partisipan kebanyakan mempunyai kebiasaan merokok. Sesuai dengan penelitian Dodie, Tendean, \& Wantouw (2013), komplikasi kronis ini biasanya terjadi pada penderita DM yang tidak terkontrol. DM disebutkan juga dapat menyebabkan terjadinya disfungsi ereksi. Jika penyakit ini terus berlanjut hingga bersifat kronis maka dapat menimbulkan komplikasi seperti gangguan psikologis dan disfungsi seksual khususnya pada pria (Dodie, Tendean, \& Wantouw, 2013). Prevalensi disfungsi ereksi pada pria diabetes sebesar $45,8 \%$ lebih tinggi daripada pada penderita non diabetes 24,1\% (Tridiantari, 2017).

Seiring dengan disfungsi seksual yang dirasakan, beberapa partisipan mengatakan mengalami ejakulasi dini baik itu cepat mengeluarkan sperma sebelum coitus atau jumlah sperma yang keluar sedikit sampai 
tidak terjadi ejakulasi meskipun sudah merasa puas dan tidak berhubungan seks dalam waktu yang lama.

Ejakulasi adalah peristiwa penyemburan air mani keluar secara mendadak yang menandai klimaks bagi pria (Suryo, 2010). Ditemukan 41\% laki-laki yang menyatakan mempunyai disfungsi ereksi juga melaporkan mempunyai ejakulasi dini, dan sekitar 30\% laki-laki yang menyatakan mempunyai ejakulasi dini juga menyatakan mempunyai disfungsi ereksi (Payne \& Sadovsky, 2007). Pria penderita ejakulasi dini mencapai klimaksnya tidak lebih dari satu atau dua menit setelah penetrasi (pemasukan penis ke dalam vagina) saat coitus. Sementara bagi pria yang prima dan sehat biasanya mencapai klimaks pada kisaran 7-10 menit setelah penetrasi (Pieter, 2011). Teori ini sama dengan partisipan (B5) bahwa mereka ejakulasi hanya 1-3 menit setelah dilakukan penetrasi dan ini akan membawa dampak secara psikologis, sosial, dan perubahan pola hubungan suami istri.

Gangguan disfungsi seksual yang lain adalah adanya gangguan hasrat/libido. Hanya partisipan B2 yang mengatakan gangguan hasrat seksual, namun itu bersifat sementara ketika ada stressor seperti perasaan kecewa dan takut tidak bisa ereksi dan ejakulasi. Penyebab gangguan hasrat seksual dapat bersifat organik atau psikososial. Penyebab organik meliputi defisiensi testosteron, penyakit kronis, penggunaan obat-obatan tertentu yang bekerja sentral, dan gangguan psikiatrik. Penyebab psikogenik meliputi stimulus yang secara psikologis bersifat represif seperti rasa cemas, marah, persepsi terhadap pasangan yang menimbulkan perasaan jijik, atau pengalaman negatif dalam berhubungan seksual (Heffner, 2008).

Tema ketiga dalam penelitian ini, yaitu dampak perubahan seksual, menunjukkan adanya dampak pada pola hubungan dengan pasangan dan terjadi perubahan peran sebagai suami. Dampak sosial terlihat pada partisipan bahwa gangguan seksual yang dialaminya membuat partisipan malu karena tidak bisa memuaskan istrinya dengan sepenuhnya. Sesuai pendapat partisipan (B1) mengatakan malu terhadap perubahan seksualnya yang dialami untuk bercanda-canda sama istri sudah malas karena takut menyinggung si istri.

Rasa malu adalah suatu keadaan yang sangat negatif dan menyakitkan serta mengakibatkan gangguan pada perilaku, kekacauan pada pemikiran, dan ketidakmampuan berbicara. Tindakan fisik yang mengikuti rasa malu adalah menjauhkan diri, seolah-olah ingin lenyap dari penglihatan orang lain. Keadaan emosional menjadi amat dalam dan memiliki pengaruh besar yang dapat merusak kepribadian, sehingga individu yang dikuasai rasa malu tersebut harus bergulat dengan keras untuk dapat membebaskan diri dari rasa malu tersebut (Albert, 2007). Selain itu partisipan (B3) mengalami kecewa terhadap perubahan seksualnya karena partisipan tidak puas terhadap hubungan seksual. Berhubungan intim bagi pasangan sangat penting untuk kesehatan. Untuk itu, setiap pasangan sebaiknya melakukan hubungan intim. Jika sudah terjadi perubahan seksual partisipan akan berdampak respon psikologis diantaranya menerima, kecewa, bingung bahkan ada juga yang stress.

Untuk mengurangi stres, orang kerap melakukan relaksasi dan meditasi. Akan tetapi, praktik-praktik ini tidak mampu meredakan stres tadi. Secara sederhana, stres menggambarkan kurangnya waktu tidur. Proses penyegaran jiwa tidak berlangsung sempurna (Hasani, 2013). Disfungsi seksual telah merubah pola dan kesejahteraan hidup partisipan, mulai adanya perubahan fisik maupun psikis. Respon tiap orang berbeda dalam menghadapinya, 
tergantung bagaimana mereka memandang seksualitas itu sendiri. Pandangan bahwa seksualitas adalah kebutuhan primer dan harus ada pada pria membuat partisipan merasa kecewa, malu, bingung bahkan stres ketika ternyata kebutuhan itu terganggu. Namun karena adanya disfungsi, maka seorang pria merasa sudah tak lagi menjadi pria sejati, dan akhirnya kesejahteraan hidup terganggu.

Tema keempat pada dalam penelitian ini, yaitu perilaku mengatasi masalah akibat perubahan seksual, menunjukkan adanya berbagai upaya yang dilakukan oleh partisipan, mulai dari mengkonsumsi obat baik untuk mengatasi diabetesnya maupun khususnya pada gangguan seksual. Selain itu, partisipan juga ada yang melakukan pengaturan diet dan mengkonsumsi telur.

Faktor resiko yang dapat menyebabkan penyakit DM meliputi faktor genetik, lingkungan, usia, obesitas, diet, kurangnya aktivitas fisik, resistensi insulin, urbanisasi dan modernisasi (Salistyaningsih, Puspitawati, \& Nugroho, 2011). Salah satunya ialah pengaturan diet yang ketat sesuai dengan aturan memang terbukti dapat mengontrol kadar glukosa darah. Hal ini dibuktikan dengan pendapat bahwa salah satu upaya pencegahan DM adalah dengan perbaikan pola makan melalui pemilihan makanan yang tepat. Semakin rendah penyerapan karbohidrat, semakin rendah kadar glukosa darah (Witasari, Rahmawaty, \& Zulaekah, 2009). Hal ini sesuai dengan hasil penelitian sebelumnya bahwa faktor perilaku dan gaya hidup, serta keadaan klinis atau mental berpengaruh terhadap kejadian DM Tipe 2 (Trisnawati \& Setyorogo, 2013). Hanya ada 1 partisipan yang mengkonsumsi telur sebagai jamu karena partisipan ingin gairahnya pulih kembali. Telur merupakan sumber yang baik untuk vitamin $\mathrm{K}$, vitamin B (biotin, thiamin, dan vitamin B12), vitamin D, selenium dan protein (Subroto, 2008).
Ungkapan teori lain bahwa telur yang umum dikonsumsi orang-orang di Asia Tenggara itu banyak dijual di pinggir jalan di Filipina. Konon ia berfungsi sebagai pembangkit gairah atau afrodisiak (Trubus, 2011). Manjur atau tidaknya afrodisiak lebih karena kekuatan sugesti, psikologis, dan emosional. Jika yakin menggunakan zat tertentu akan meningkatkan kehidupan seks, maka dapat membantu membawa hasrat dan gairah seksual, setidaknya jangka panjang (Triyanto, 2011).

Terdapat beberapa pengalihan masalah yang dilakukan partisipan dalam menghadapi perubahan yang dirasakan seperti melakukan aktivitas spiritual dan aktivitas lain. Aktivitas spiritual dilakukan dengan meningkatkan hubungan dengan Tuhan seperti dzikir, sholat, doa dan pengajian terhadap perubahan yang dialami partisipan. Partisipan B3 yang mengatakan bahwa penyakit ini sudah pemberian dari Tuhan karena telah menyadari konsekuensi dari DM. Salah satu penelitian berpendapat bahwa salah satu sumber kebermaknaan hidup adalah keyakinan akan keberadaan Tuhan. Pendekatan diri kepada Tuhan adalah mengembalikan manusia kepada naluri dasarnya, yaitu insting keberagamaan. Naluri ini mendorong manusia untuk mengadakan kegiatan keberagamaan, karena manusia beragama pada dasarnya adalah manusia yang struktur mental keseluruhan dan kehidupannya diarahkan kepada Tuhan (Kurniawan \& Widyana, 2014). Spritualitas memberi dimensi luas pada pandangan holistik kemanusiaan. Nilai yang membentuk dan memengaruhi kehidupan adalah nilai keabadian dan kesehatan Potter \& Perry (2005). Penelitian sebelumnya menunjukkan bahwa sebanyak $92 \%$ responden mempunyai tingkat spiritualitas yang tinggi dan sisanya memiliki spiritualitas yang rendah. Hal ini menunjukkan umumnya pasien yang 
memiliki penyakit kronis mempunyai tingkat spiritualitas yang baik (Suciani \& Nuraini, 2017). Ungkapan partisipan B4 dan B7 ini sangat didukung oleh keyakinannya bahwa sholat bisa menahan nafsu dan menahan diri dari perbuatan keji. Bukan berarti seksualitas adalah suatu kejelekan, akan tetapi dengan libido yang tinggi dan begitu banyak godaan yang menstimulasi dirinya, termasuk hasrat yang menggebu dalam hatinya itu semua mampu ditahan dan diatasi dengan sholat. Dengan sholat seseorang akan merasa lebih tenang dan bisa berkomunikasi langsung dengan Tuhan.

Pada penelitian ini partisipan mengharapkan adanya perubahan dari diri sendiri dan istri sebagai pasangan, sesuai dengan tema kelima hasil penelitian. Harapan atas diri sendiri ditekankan pada kemampuan bersabar, dan mendapatkan rizki yang banyak untuk memenuhi kebutuhan berobat sehingga tetap dapat mengontrol kadar gula darah dan penyakitnya, sehingga fungsi seksualnya juga dapat berubah lebih baik, selain itu partisipan juga berharap sembuh dan kembali berfungsi.

Harapan akan kesembuhan membuat seseorang tidak ragu meminum obat yang pahit. Harapan akan ridha dan surga-Nya menjadikan seseorang sanggup melawan hawa nafsu dan menaati Tuhannya. Harapan, dengan demikian, merupakan obat mujarab hidup, membangkitkan semangatnya, dan meringankan beban-bebannya. Adanya harapan membuat hidup jadi ceria dan penuh warna. Sungguh sempit hidup tanpa lapangnya harapan (Badruzaman, 2017).

Sebagian besar partisipan tetap menginginkan adanya peran dari istri dengan tetap memberi kasih sayang, menerima serta memberi kasih sayang untuk mengatasi perubahan seksualnya. Harapan ini bukanlah harapan kosong, namun kehadiran pasangan yang seutuhnya sangat memengaruhi respon psikologis, sehingga akan didapatkan hubungan dan kehidupan pasangan yang baik dan sehat. Sepasang suami istri mengungkapkan perasaan yang telah diciptakan oleh Allah sebagai bagian yang lumrah dari sebuah kenikmatan yang halal pada saat senggama antara pasangan suami istri secara terbuka, menambah hasrat suami pada istrinya dan kedua belah pihak dapat menikmati bersama dan menggapai kepuasan jiwa dan seksual setinggi mungkin (Sa'id, 2012).

Tema keenam dalam penelitian ini pasangan hidup menjadi support system terdekat bagi partisipan. Respon apapun yang ditunjukkan akan membuat perubahan yang sangat penting bagi partisipan untuk melalui hari-harinya bersama permasalahan yang dialaminya. Respon istri akan mengakibatkan suami merasa rendah diri, putus asa bahkan membiarkan istri untuk melakukan hal apapun asal tidak mengganggu kehidupan partisipan sehari-hari. Juga adanya pengobatan menjadi harapan bagi partisipan yang lain di samping memberikan kasih sayang, memberi solusi dan menerima. Maka dari respon suami dan perubahan seksualnya tersebut muncul berbagai respon istri diantaranya diam, menerima, tidak menuntut bahkan ada yang marah-marah.

Bentuk support system bukan hanya respon istri namun melibatkan respon keluarga juga berperan penting terhadap penyakit yang dialami partisipan. Dukungan terhadap program pengobatan yang dilakukan serta komunikasi yang baik dan jelas sesama anggota keluarga. Dukungan keluarga yang tinggi tentunya akan memberikan ketenangan dan kenyamanan pada pasien DM tersebut. Dukungan sosial keluarga yang adekuat terbukti berhubungan dengan menurunnya mortalitas lebih mudah sembuh dari sakit dan kesehatan emosi. Dukungan keluarga yang diterima seseorang dapat berupa dukungan informasional, 
perhatian, fasilitas, dan dukungan emosional (Suardana, Rasdini, \& Kusmarjathi, 2015). Hasil penelitian sebelumnya menunjukkan bahwa dukungan keluarga merupakan faktor paling dominan dalam mempengaruhi kadar gula darah dan prediktor terkuat dalam memengaruhi hasil kesehatan pasien, utamanya dengan penyakit kronis (Isworo \& Saryono, 2010). Hasil penelitian Mamahit pada tahun 2018 menunjukkan bahwa dampak negatif yang dapat timbul jika pasien tidak mendapatkan dukungan keluarga secara utuh antara lain pasien cenderung akan merasa tertekan bahwa tidak ada yang memerhatikan kondisinya dan hal ini dapat memengaruhi kesehatan tubuhnya. Jadi, keluarga diharapkan dapat memenuhi semua kebutuhan kesehatan guna meningkatkan kualitas hidup dan mencegah penyakit (Mamahit, 2018).

\section{SIMPULAN}

Pada penelitian ini ditemukan enam tema yaitu: 1) pandangan tentang seksual pada kehidupan pria; 2) gambaran perubahan seksual yang dialami; 3) dampak perubahan seksual yang dialami; 4) perilaku mengatasi masalah akibat perubahan seksual; 5) harapan terhadap kondisi perubahan seksual; 6) respon support system.

Penelitian ini merekomendasikan perlu adanya sistem yang mendukung perawat untuk mengkaji dan menyelesaikan masalah seksual pada klien pria diabetes, sehingga perawat dapat melakukan proses keperawatan seksualitas pada klien DM dan dapat memasukkan masalah seksual ke dalam pelayanan kesehatan dan proses keperawatan sehingga terintegrasi dan paripurna. Perlu adanya dokumentasi dan format tersistem tentang seksualitas, sehingga perawat dapat mudah mengisi dan mengkaji seksualitas. Sebagai kelengkapan proses pengkajian, perlu disusun format pengkajian baku untuk menggali kebutuhan seksual klien pria dengan DM. Masalah seksual pasien sampai saat ini masih belum mendapatkan perhatian khusus, diperlukan kajian lebih lanjut untuk mengidentifikasi secara lebih jelas dampak yang ditimbulkan akibat perubahan seksual. Hal ini dapat dilakukan dengan mengembangkan kurikulum dalam institusi pendidikan keperawatan.

Institusi Pendidikan diharapkan meningkatkan kesadaran pada mahasiswa bahwa kebutuhan seksual merupakan salah satu kebutuhan dasar manusia, sehingga dapat lebih sadar dalam memberikan asuhan keperawatan. Peserta didik perlu diajarkan untuk mampu melakukan pengkajian terkait dengan masalah seksual partisipan dengan ulkus diabetikum. Selain itu, mahasiswa perlu dimonitor dan diberikan bimbingan saat mengimplementasikan asuhan keperawatan pasien dengan masalah seksual. Penelitian ini dapat dilanjutkan dengan tema sejenis misalnya dengan pengalaman disfungsi seksual pada klien perempuan dengan ulkus diabetikum.

\section{DAFTAR PUSTAKA}

Ahsin. (2007). Fikih Kesehatan. Jakarta: Kuntum Media.

Amelia, K. R (2019). Self-Monitoring of Blood Glucose Dalam Mencegah Neuropati Pada Ekstremitas Bawah Pasien Diabetes Mellitus Tipe 2 (Tesis). Universitas Muhammadiyah Jakarta, Jakarta, Indonesia.

Asmadi. (2008). Tehknik Prosedural Keperawatan: Konsep Dan Aplikasi Kebutuhan Dasar Klien. Jakarta: Salemba Medika.

Badruzaman, A. (2017). Kesalehan Sosial di Balik Ketaatan Ritual. Jakarta: Elex Media Komputindo.

Bijlsma-Rutte A, Braamse, A. M. J., van Oppen, P., Snoek, F. J., Enzlin, P., Leusink, P., Nijpels, G., Elders, P. J. M. (2017). Screening For Sexual 
Dissatisfaction Among People With Type 2 Diabetes In Primary Care. Journal of Diabetes and Its Complications. J Diabetes Complications, 31(11): 1614-1619. doi: 10.1016/j. jdiacomp.2017.07.020.

Dodie, N. J., Tendean, L., \& Wantouw, B. (2013). Pengaruh Lamanya Diabetes Melitus Terhadap Terjadinya Disfungsi Ereksi. Ebiomedik, 1(3): 1120-1125.

Fox, C. (2010). Bersahabat Dengan Diabetes Mellitus Tipe 2. Jakarta: Penebar Plus.

Hasani, S. (2013). Memahami Mimpi. Yogyakarta: LKiS printing cemerlang.

Heffner, L. J. (2008). At a Glance Sistem Reproduksi Ed.2. Jakarta: Erlangga.

Hinchliff, S., Tetley, J., Lee, D., Nazroo, J., Hinchliff, S., Tetley, J., \& Nazroo, J. (2018). Older Adults' Experiences of Sexual Difficulties: Qualitative Findings From the English Longitudinal Study on Ageing ( ELSA). J Sex res, 55(2): 152-163. doi: 10.1080/00224499.2016.1269308

International Diabetes Federation. (2017). IDF Diabetes Atlas Eighth edition 2017. Retrieved from http://www. diabetesatlas.org/resources/2017atlas.html

Isworo, A. \& Saryono. (2010). Hubungan Depresi dan Dukungan Keluarga Terhadap Kadar Gula Darah pada Pasien Diabetes Melitus Tipe 2 di RSUD Sragen. Jurnal Keperawatan Soedirman, 5(1): 37-46.

Kementrian Kesehatan Republik Indonesia. (2018). Laporan Utama Hasil Riset Kesehatan Dasar tahun 2018 Jakarta: Badan Penelitian dan Pengembangan Kesehatan.

Kurniawan, W., \& Widyana, R. (2014). Pengaruh Pelatihan Dzikir Terhadap Peningkatan Kebermaknaan Hidup
Pada Mahasiswa. Jurnal Intervensi Psikologi(JIP), 5(2): 67-88.

Mahendra. (2008). Care Your Self: Diabetes Mellitus. Jakarta: Penebar Plus.

Mamahit, G. (2018). Dukungan Keluarga Dengan Kepatuhan Terapi Insulin Pasien Diabetes Melitus Tipe 2. e-Journal (e-Kep) 6(1).

Maslow, A. H. (1943). A theory of human motivation. Psychological Review, 50(4): 370-390. Doi: 10.1037/ h0054346.

Muchtar. (2009). Rahasia Hidup Sehat \& Bahagia. Jakarta: Bhuana IImu Populer.

Payne, R. E., \& Sadovsky, R. (2007). Identifying and Treating Premature Ejaculation: Importance of The Sexual History. Cleveland Clinic Journal of Medicine, 74(3): 47-53.

Permatasari, S. M., Sudargo, T., \& Purnomo, L. B. (2015). Estimasi Asupan Indeks Glikemik Dan Beban Glikemik Dengan Kontrol Gula Darah Pasien Diabetes Melitus Tipe 2. Jurnal Gizi Klinik Indonesia, 12(2): 45-53.

Pieter, H. Z. (2011). Pengantar Psikopatologi Untuk Keperawatan. Jakarta: Kencana.

Potter, P.A \&.Perry A.G. (2005). Buku Ajar Fundamental Keperawatan Konsep, Proses, dan Praktik Ed.4. Vol.1. Jakarta: EGC.

Rahardjo, W., Saputra, M., \& Hapsari, I. (2015). Harga Diri, Sexting dan Jumlah Pasangan Seks yang Dimiliki oleh Pria Lajang Pelaku Perilaku Seks Berisiko. Jurnal Psikologi, 42(2): 101-114.

Rahman, H. F., \& Sukmarini, L. (2017). Efikasi Diri, Kepatuhan, dan Kualitas Hidup Pasien Diabetes Melitus Tipe 2 (Self Efficacy, Adherence, and Quality of Life of 
Patients with Type 2 Diabetes). E-Jurnal Pustaka Kesehatan, 2: 108-113.

Robert H Albert. (2007). Malu. Yogyakarta: Kanisius.

Rowland, D. L., \& Incrocci, L. (2008). Handbook of Sexual and Gender Identity Disorder. Canada: John Wallery \& Sons, Inc.

Sa'id, M (2012). Hidup Bahagia Hingga Akhir Hayat. Jakarta: Akbar Media Eka Sarana.

Salistyaningsih, W., Puspitawati, T., Nugroho, D. K., (2011). Hubungan Tingkat Kepatuhan Minum Obat Hipoglikemik Oral dengan Kadar Glukosa Darah pada Pasien Diabetes Melitus Tipe 2. Berita Kedokteran Masyarakat, 27(4): 215-221.

Suardana, I. K., Rasdini, I. G. A. A., \& Kusmarjathi, N. K. (2015). Hubungan Dukungan Sosial Keluarga Dengan Kualitas Hidup Pasien Diabetes Melitus Tipe II. di Puskesmas IV Denpasar Selatan. Jurnal Skala Husada, 12 (1): 96-102.Subroto, M. A. (2008). Real Food True Health-Makanan Sehat Untuk Hidup Lebih Sehat. Yogyakarta: AgroMedia Pustaka.

Suciani, T., \& Nuraini, T. (2017). Kemampuan Spiritualitas Dan Tingkat Stres Pasien Diabetes Mellitus Di Rumah Perawatan: Pendahuluan. Jurnal Keperawatan Indonesia, 20(2): 102109.

Suryo, J. (2010). Herbal Penyembuh Impotensi \& Ejakulasi Dini. Yogyakarta: PT Bentang Pustaka.
Taluta, Y. P. \& Hamel, R. S. (2014). Hubungan Tingkat Kecemasan dengan Mekanisme Koping pada Penderita Diabetes Melitus Tipe II di Poliklinik Penyakit Dalam Rumah Sakit Umum Daerah Tobelo Kabupaten Halmahera Utara. E journal keperawatan (e-Kp), 2(1).

Tridiantari, D. K. (2017). Gambaran Karakteristik Responden dengan Kejadian Disfungsi Ereksi pada Laki-laki Penderita Diabetes Mellitus di Kota Semarang. Jurnal Kesehatan Masyarakat, 5: 96-101.

Trisnawati, S. K. \& Setyorogo, S. (2013). Faktor Risiko Kejadian Diabetes Melitus Tipe II di Puskesmas Kecamatan Cengkareng Jakarta Barat Tahun 2012. Jurnal IImiah Kesehatan, 5(1): 6-11.

Triyanto, B. (2011). Love Food 101 Makanan Pembangkit Gairah Cinta. Jakarta: Gramedia Widasarana.

Trubus. (2011). Trubus Exo Itik Duo-Bisa Pedaging, Bisa Petelur. Jakarta: Trubus.

Witasari, U., Rahmawaty, S., \& Zulaekah, S. (2009). Hubungan Tingkat Pengetahuan, Asupan Karbohidrat dan Serat dengan Pengendalian Kadar Glukosa Darah pada Penderita Diabetes Melitus Tipe 2. Jurnal Penelitian Sains \& Teknologi, 10(2): 130-138. 